JEL Classification: M31, M37

DOI: 10.46361/2449-2604.8.2.2021.62-71

\section{NINO TCHANTURIA}

Caucasus International University

Ph.D. Student

Tbilisi, Georgia

E-mail: tchanturia.nino@ciu.edu.ge

orcid.org/0000-0003-1894-5822

Edited by:

June, 2021

Reviewed by:

June, 2021

\section{THE ROAD FROM TRADITIONAL MARKETING TO DIGITAL MARKETING}

The 21st century is considered to be the century of the consumer because the existence of companies today depends on the demand of the consumer. For any business to succeed, it is essential to keep abreast of market trends, and use all effective ways of delivering information. Always be where its potential customers are.

We therefore aim to explore the role of digital marketing in the modern world and show its role in the daily lives of consumers. Which factors will be decided by consumers to buy online and not the traditional method. The aim of the research is to determine the attitude of consumers towards digital marketing. 178 people participated in the study. Primary data obtained through both secondary and online questionnaires were processed. Research has shown that digital marketing can achieve more if it prioritizes consumer desires.

Key words: Digital Marketing, Traditional Marketing, Customer behavior, Striking Trend 
JEL Classification: M31, M37

DOI: 10.46361/2449-2604.8.2.2021.62-71

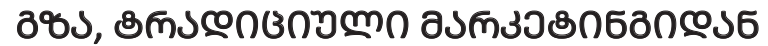

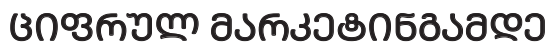

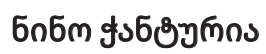

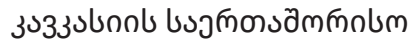

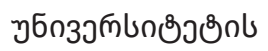

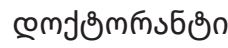

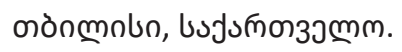

E-mail: tchanturia.nino@ciu.edu.ge

orcid.org/0000-0003-1894-5822

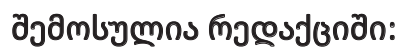

o36olo, 2021

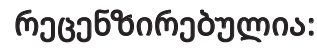

o3mobo, 2021

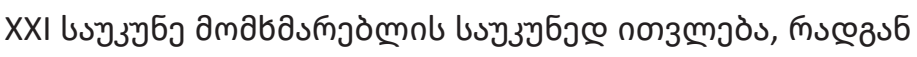

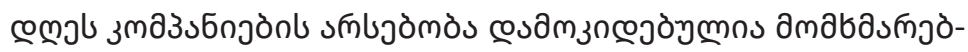

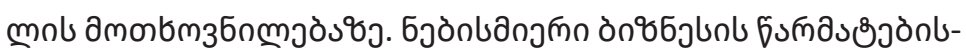

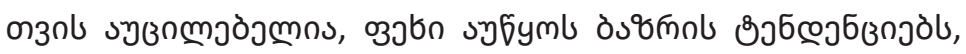

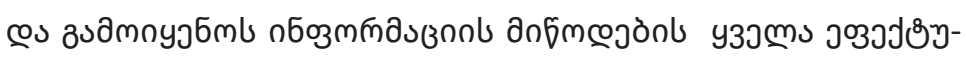

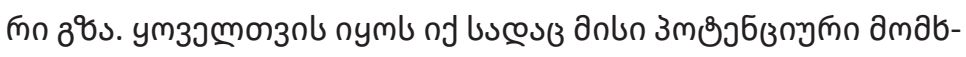

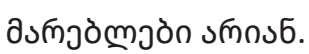

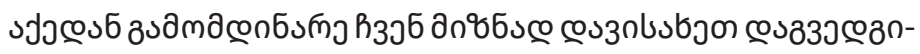

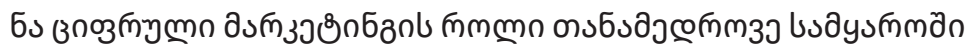

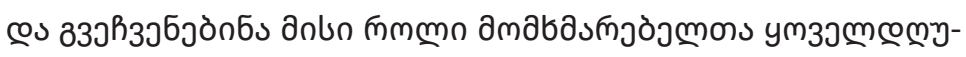

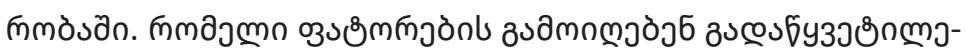

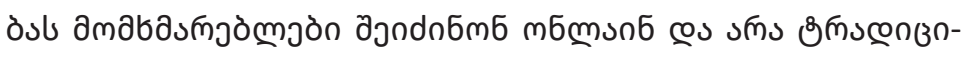

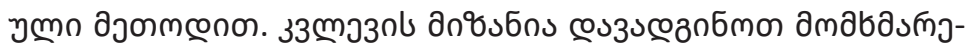

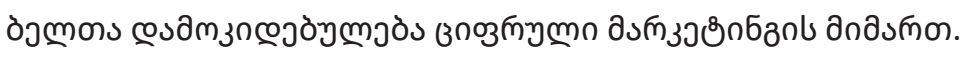

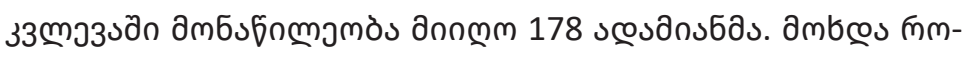

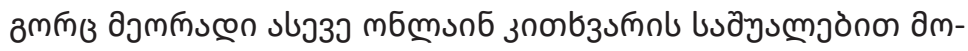

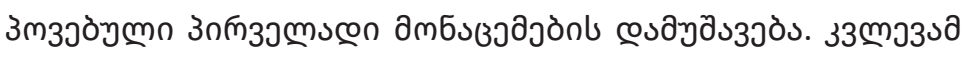

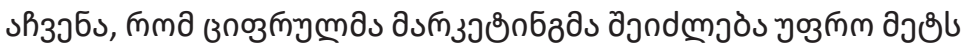

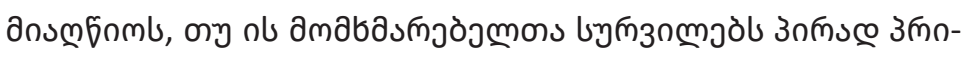

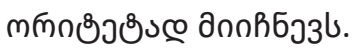

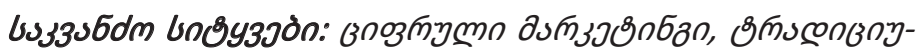

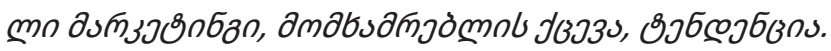




\section{วอนJ3smn}

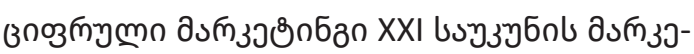

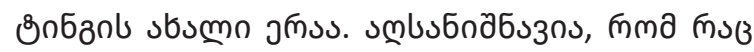

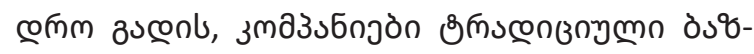

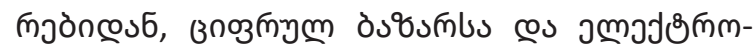

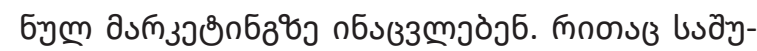

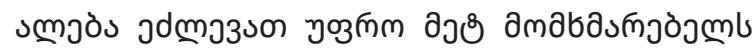

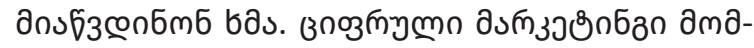

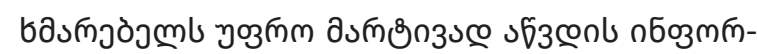

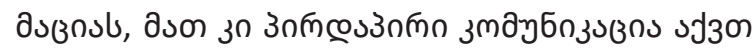

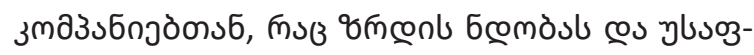

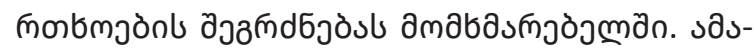

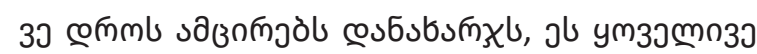

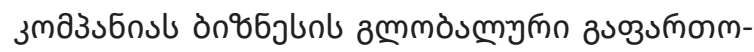

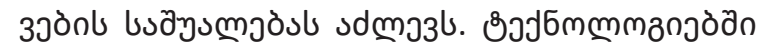

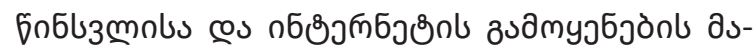

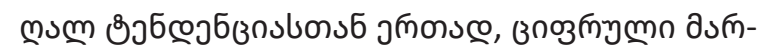

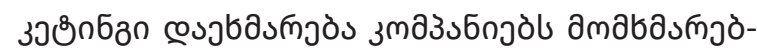

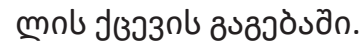

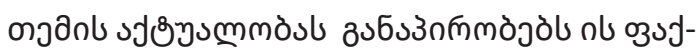

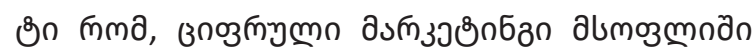

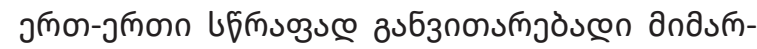

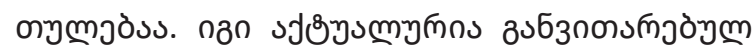

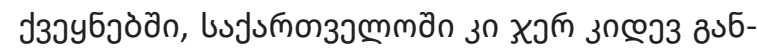

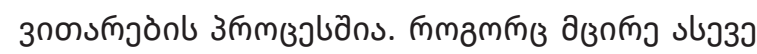

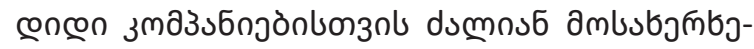

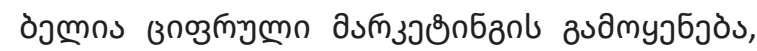

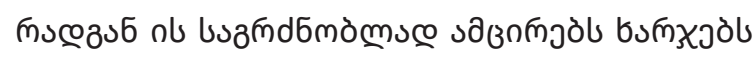

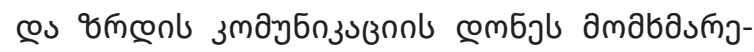

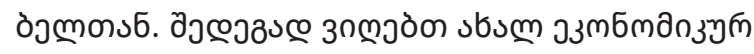

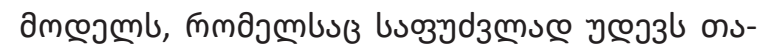

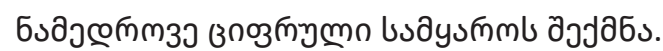

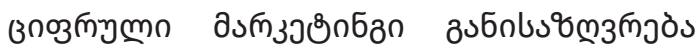

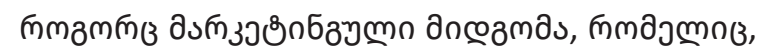

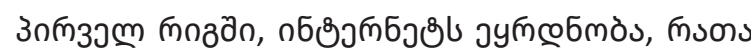

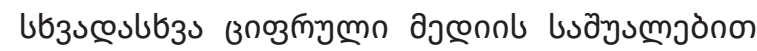

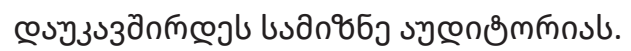

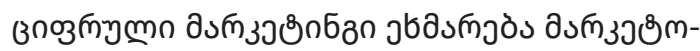

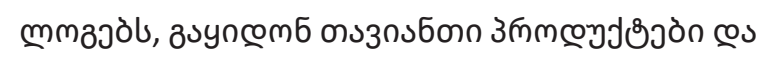

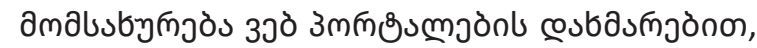

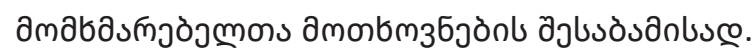

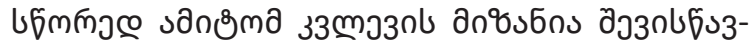

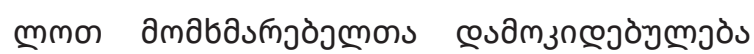

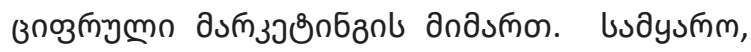

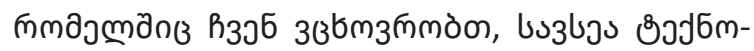

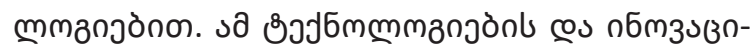

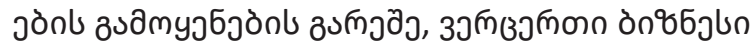

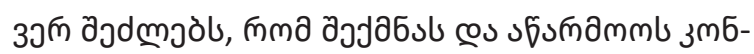

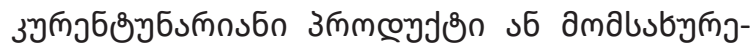

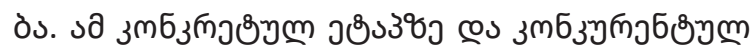
bsaysmmàn do

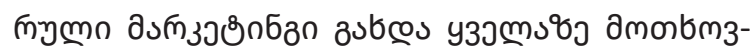

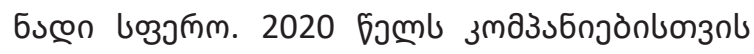

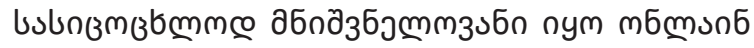

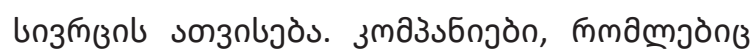

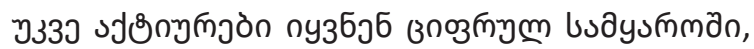

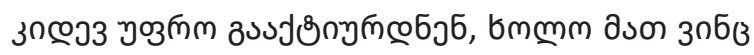

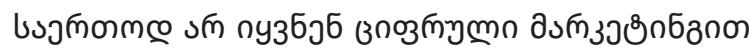

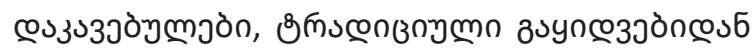

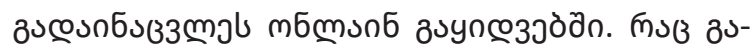

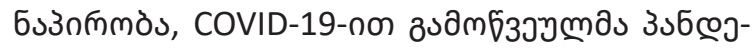

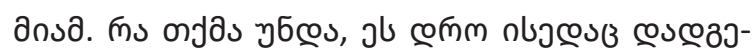

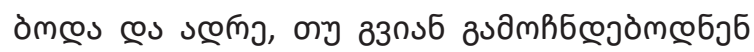

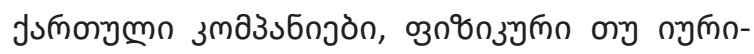

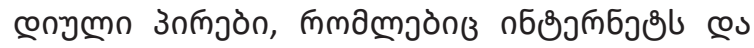

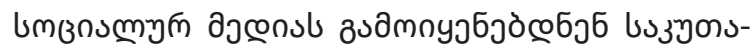

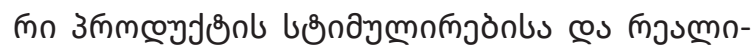

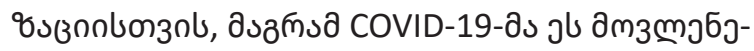

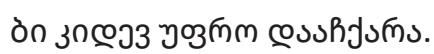

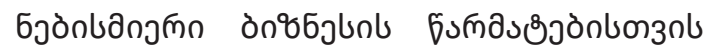

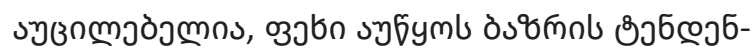

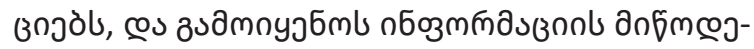

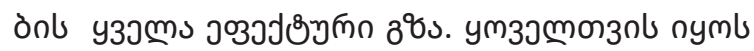

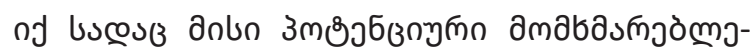

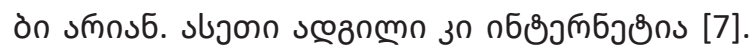

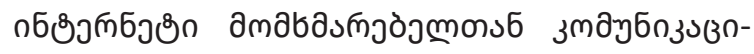

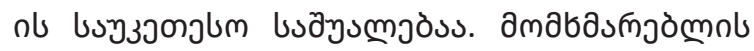

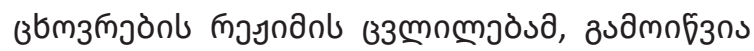

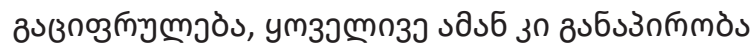

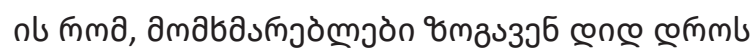

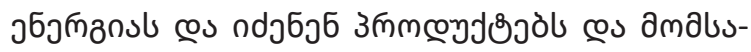

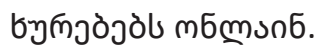




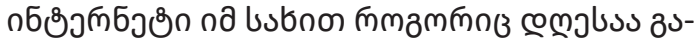

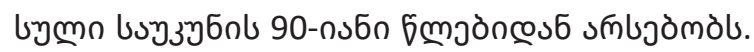

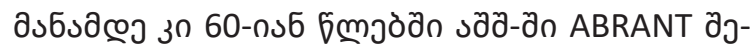

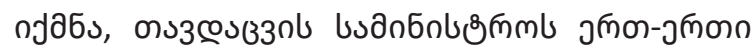

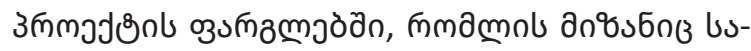

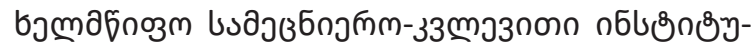

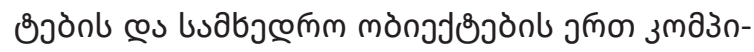

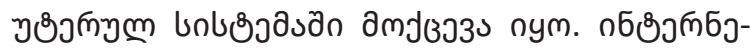

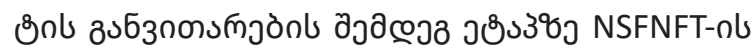

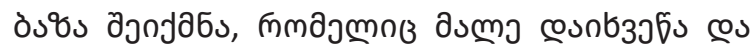

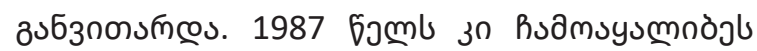

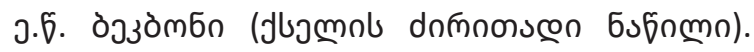
ة

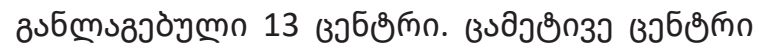

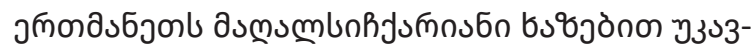

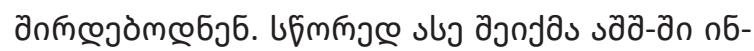

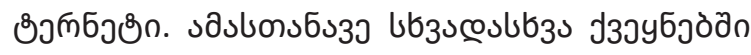

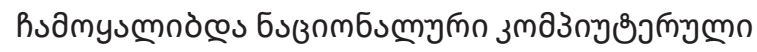

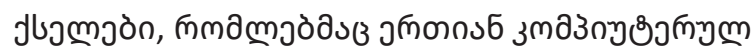

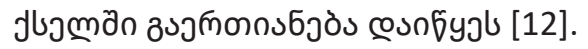

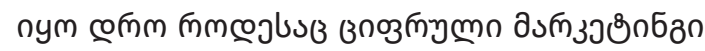

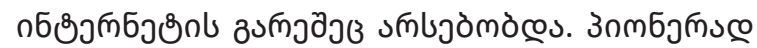

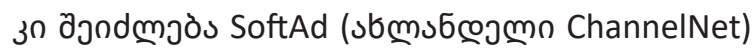

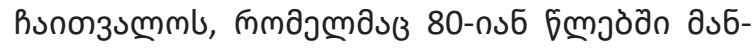

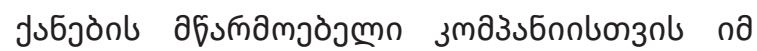

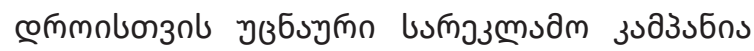

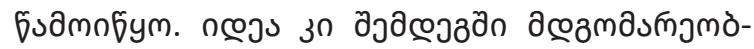

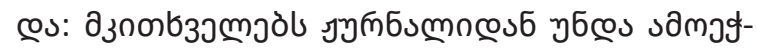

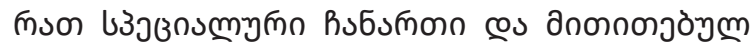

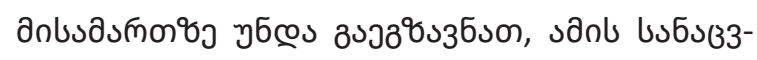

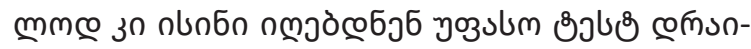

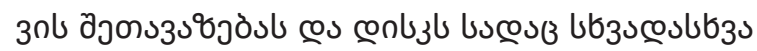

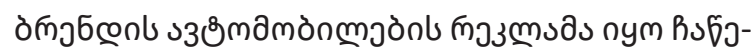

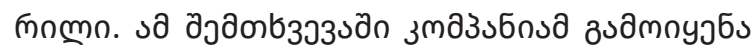

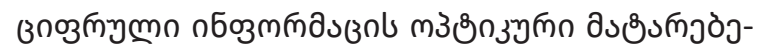

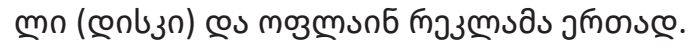

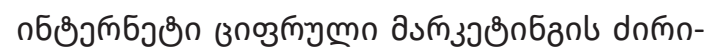

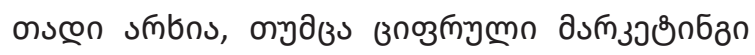

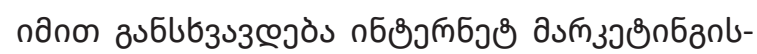

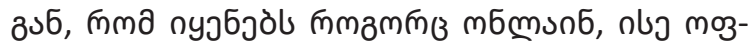

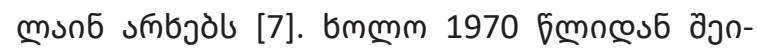

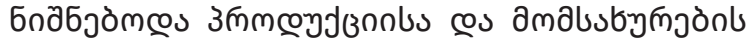

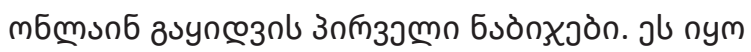

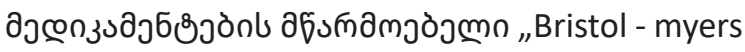

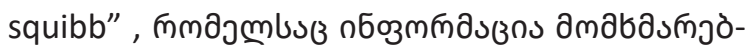

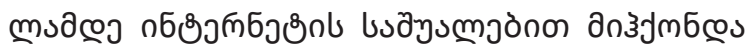
[9].

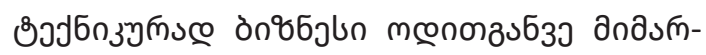

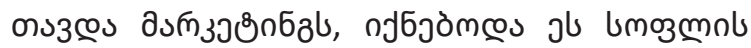

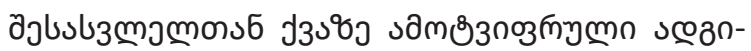

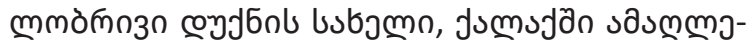

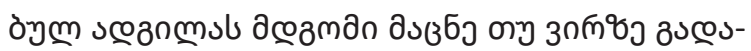

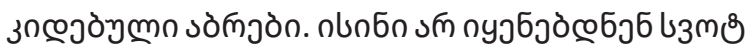

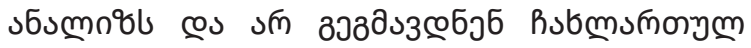

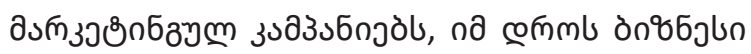

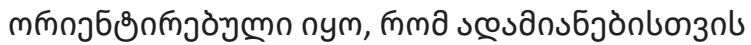

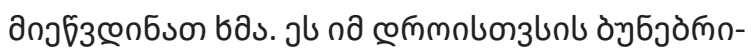

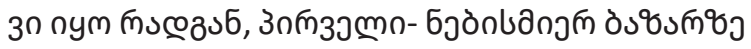
змбทตூว

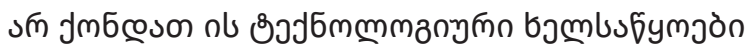

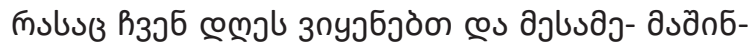

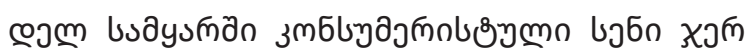

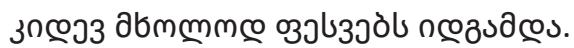

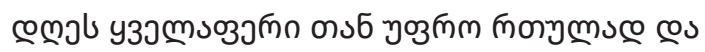

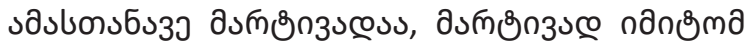

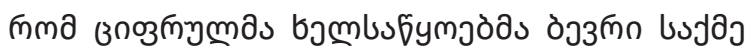

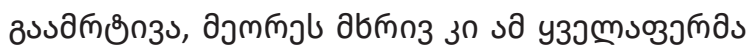

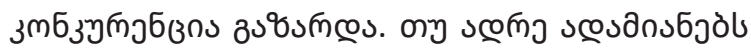

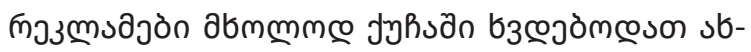

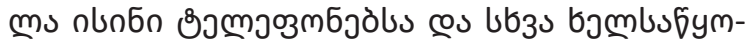

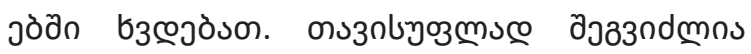

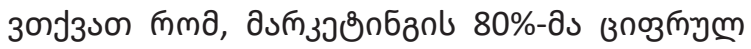

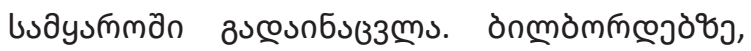

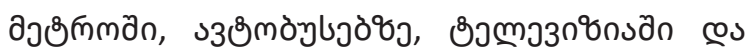

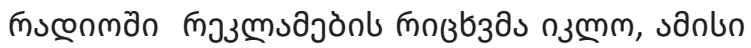

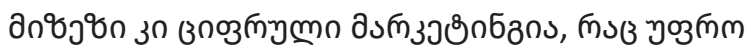

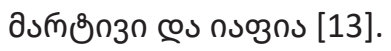

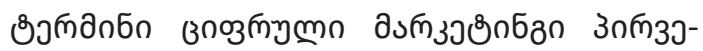

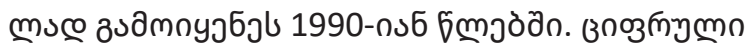

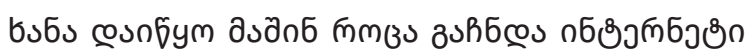
œu Web 1.0 з

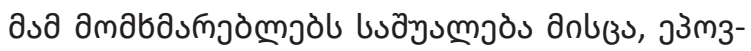




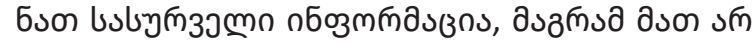

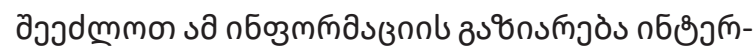

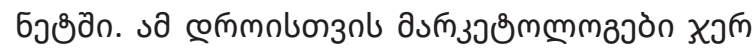

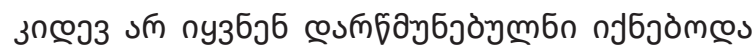

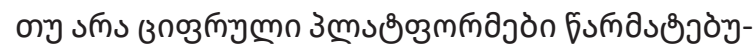

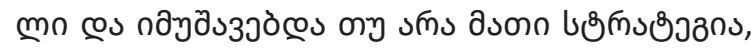

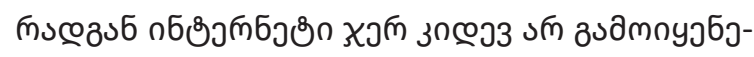

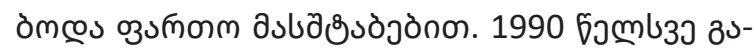

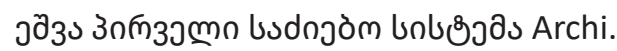

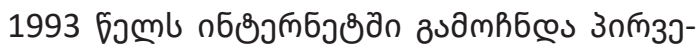

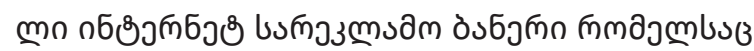

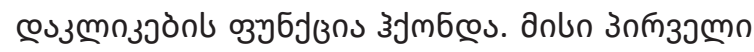

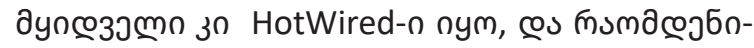

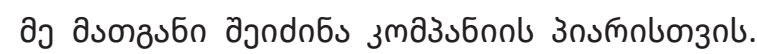

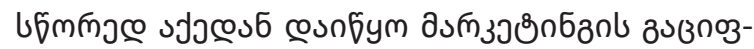

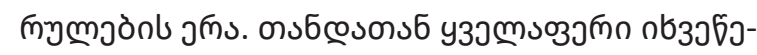

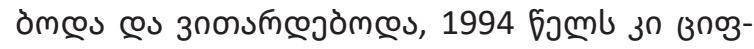

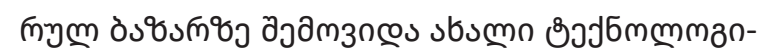

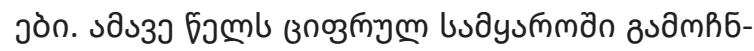

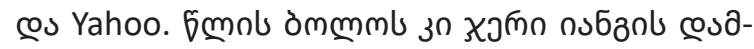

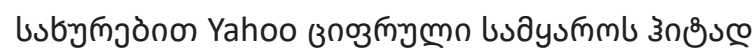

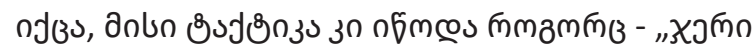

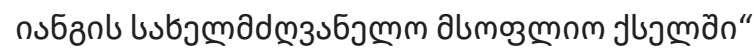
("Jerry's Guide to the World Wide Web"). пбఠిวm-

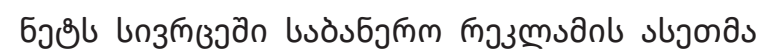

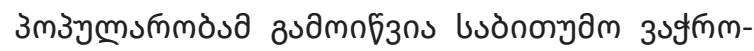

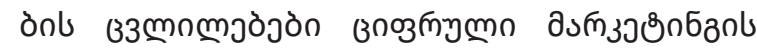

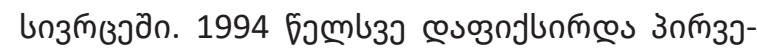

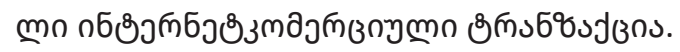

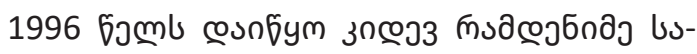

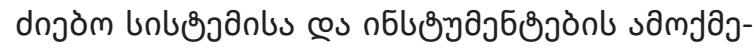

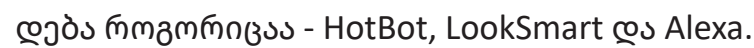

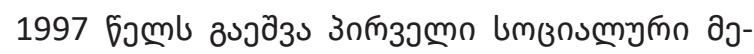

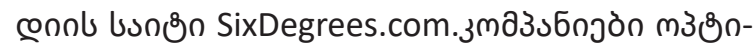

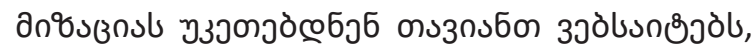

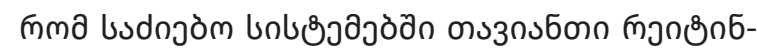

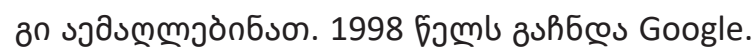

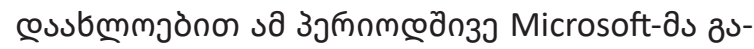

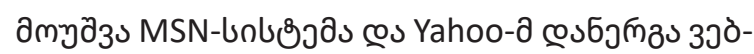

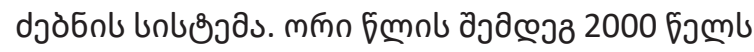

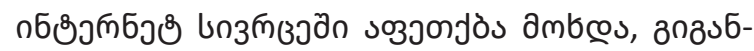

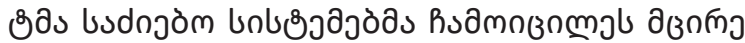

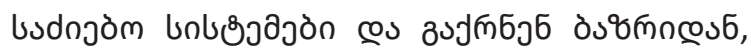

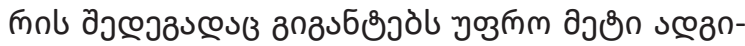

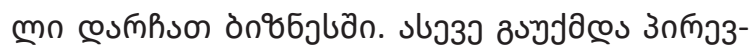

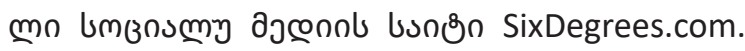

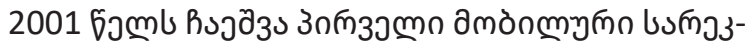
muam 3دaзsбns (Universal Music). 2020 6jmb

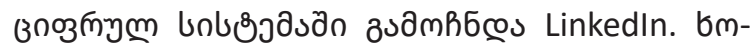

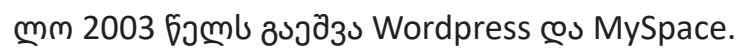

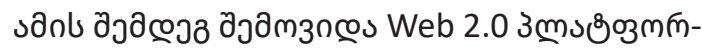

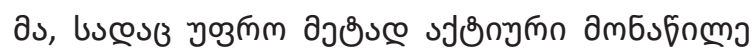

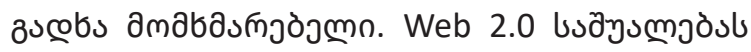

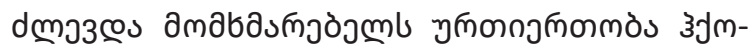

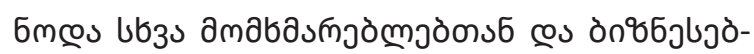

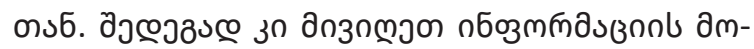

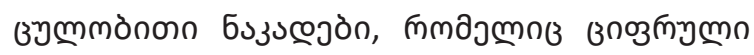

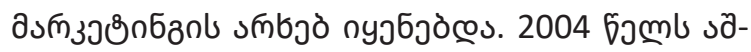

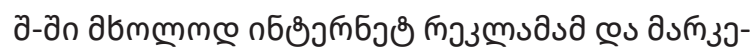

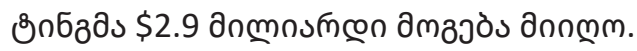

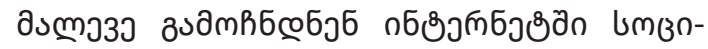

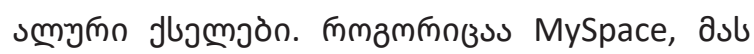

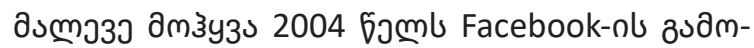

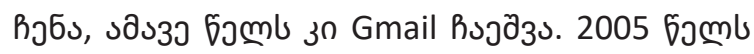

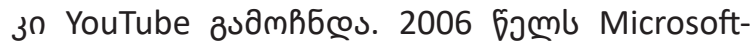

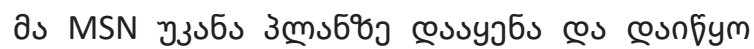

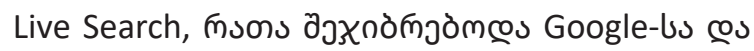

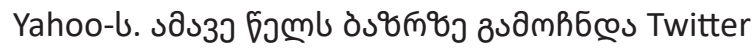
œu Amazon-nb zuyn@

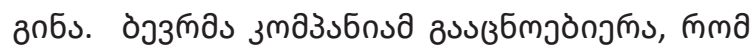

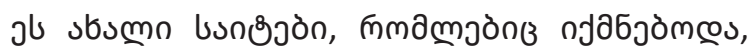

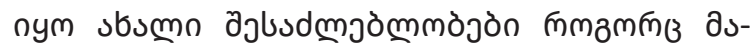

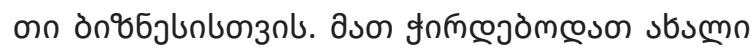

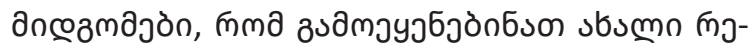

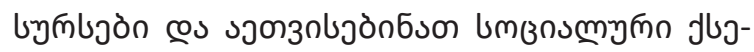

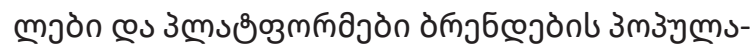

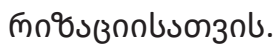

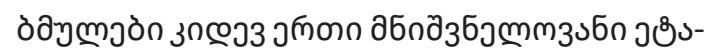

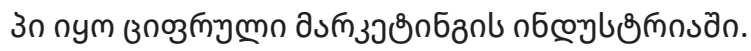

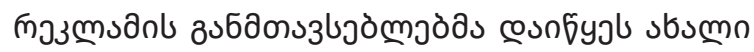

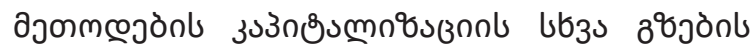

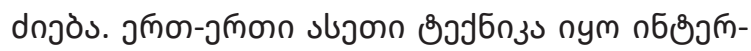




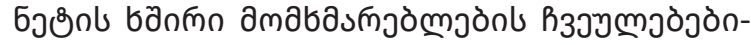

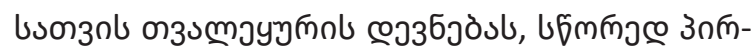

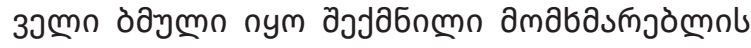

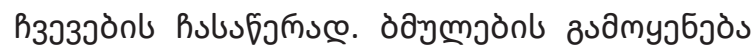

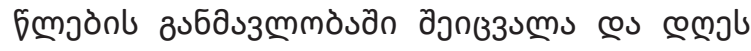

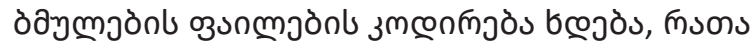

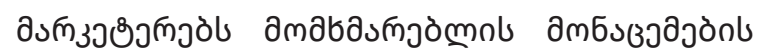

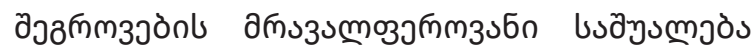

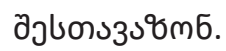

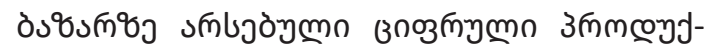

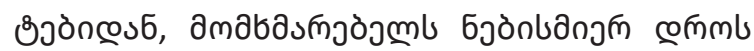

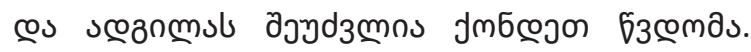

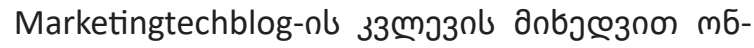

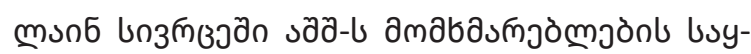

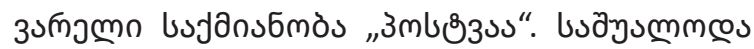

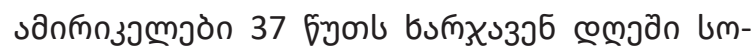

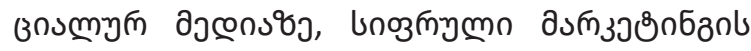

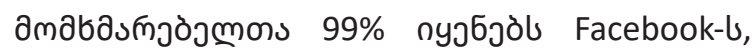
97\% - Twitter, 69\% nујбృठ̀- Pinterest, bmmm

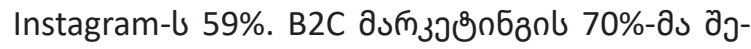
ndnбs Facebook-nb bsàumjònnon, 67\% djodn6s

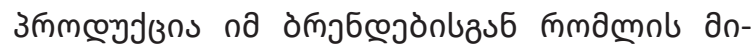

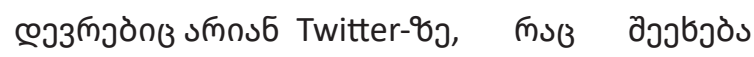

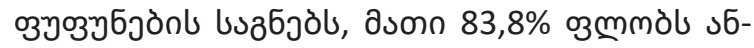

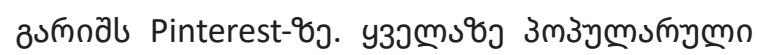

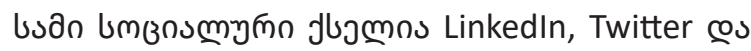
Facebook.

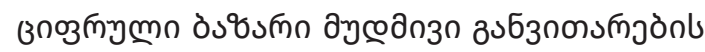

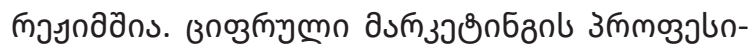

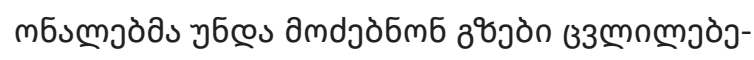

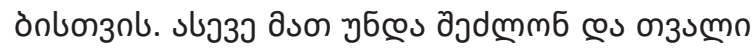

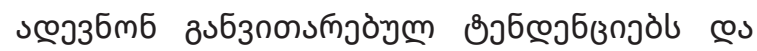

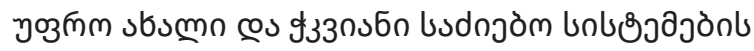

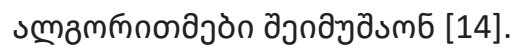

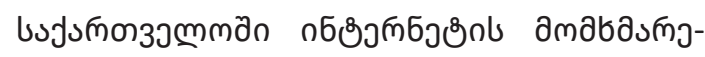

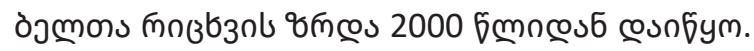

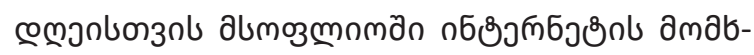

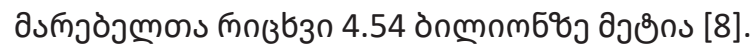

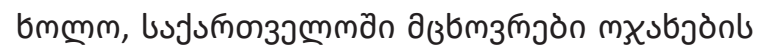

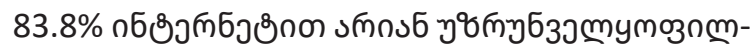

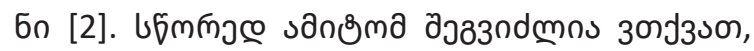

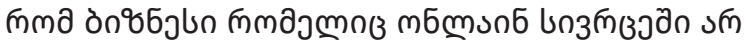

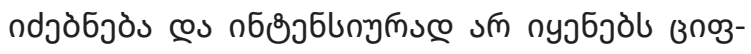

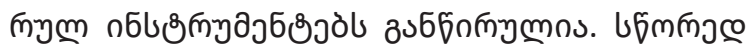

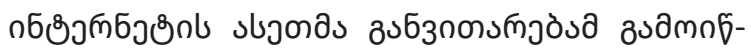

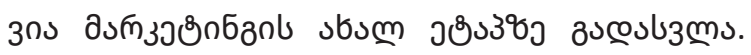

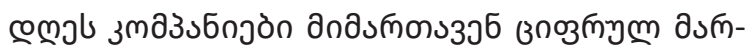

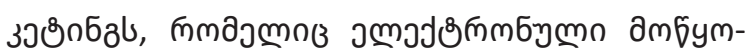

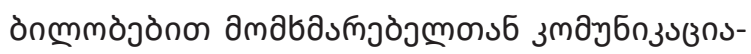

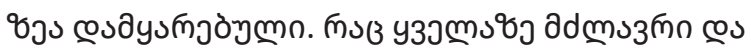

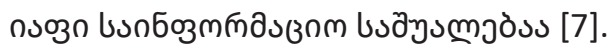

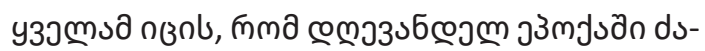

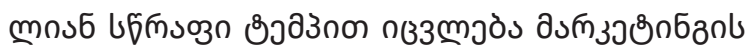

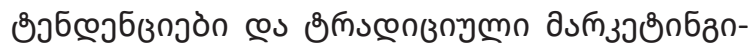

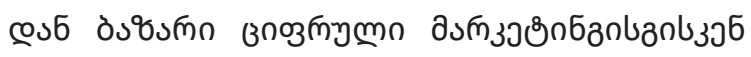

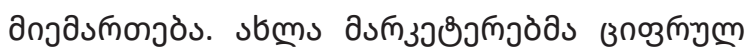

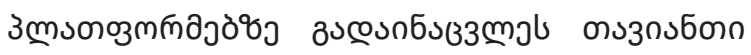

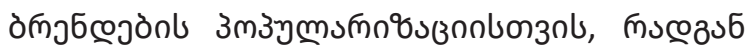

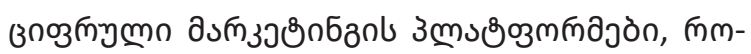

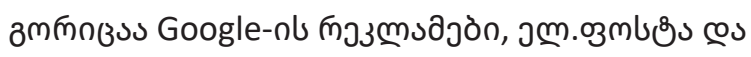

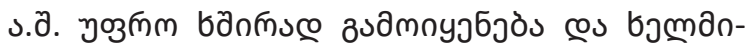

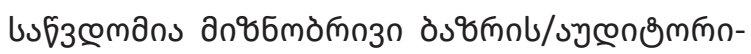

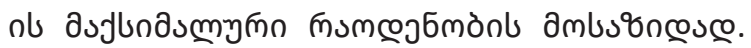

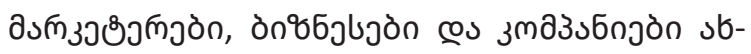

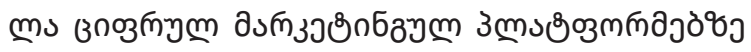

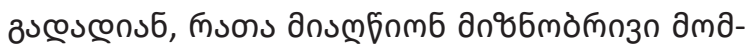

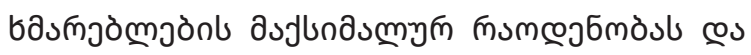

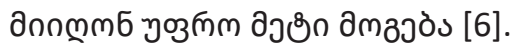

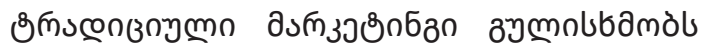

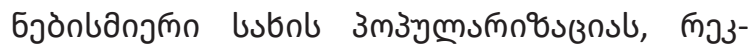

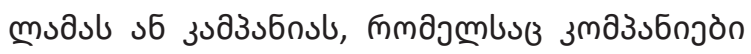

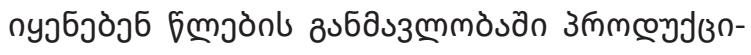

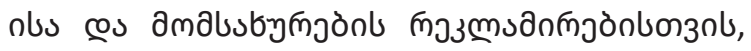

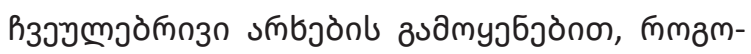

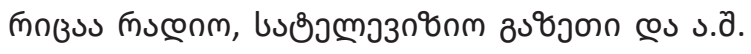

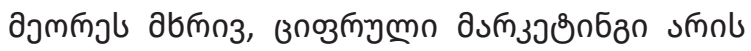

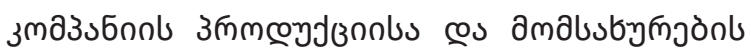

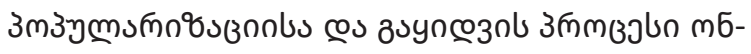

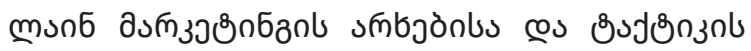

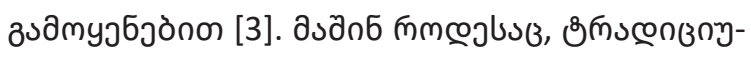

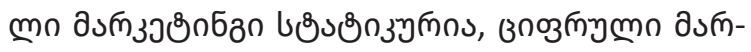

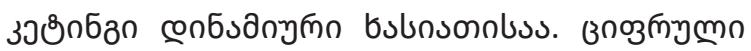

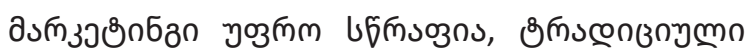




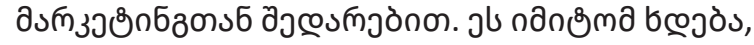

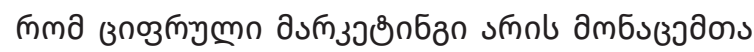

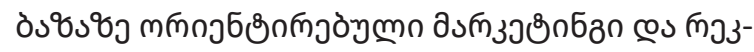

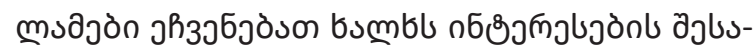

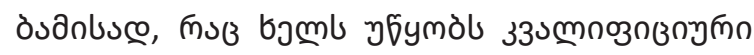

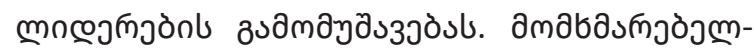

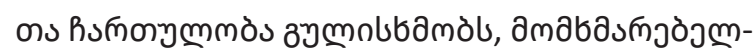

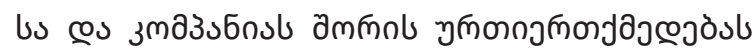

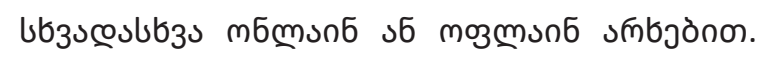

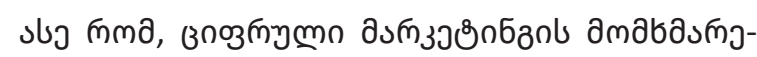

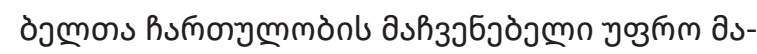

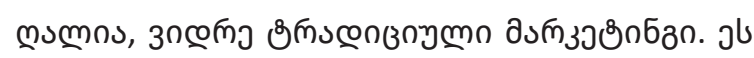

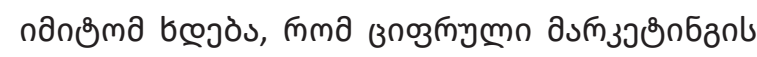

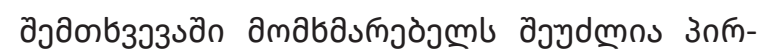

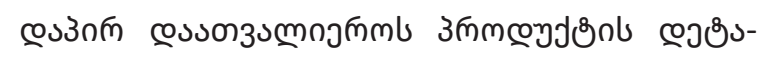

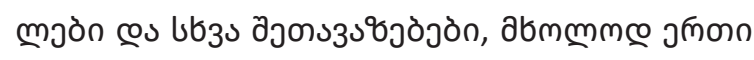

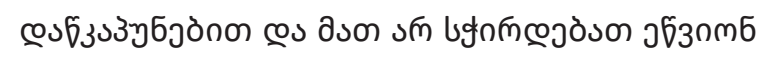

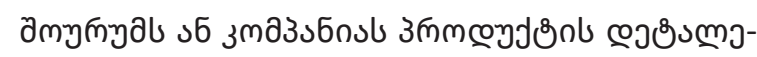

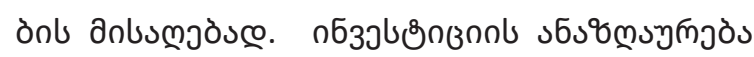

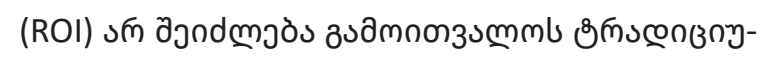

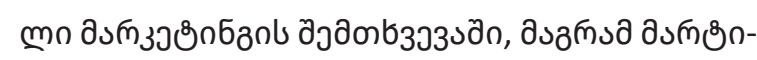

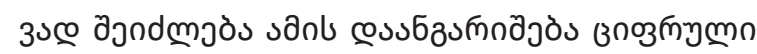

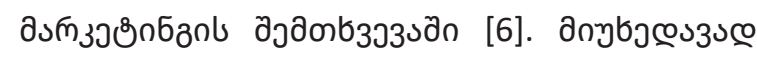

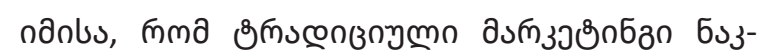

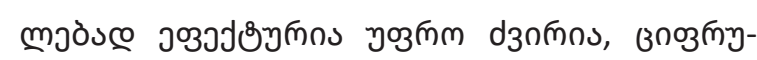

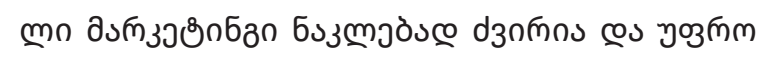

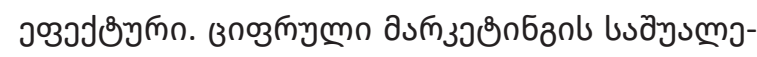

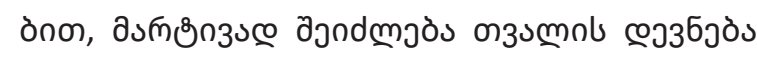

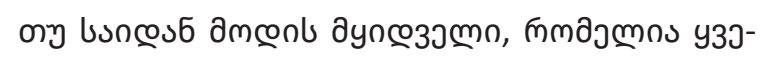

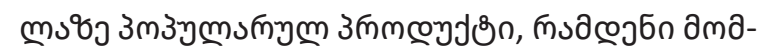

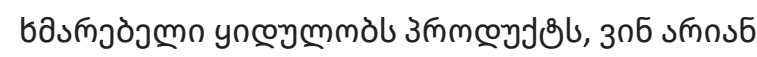

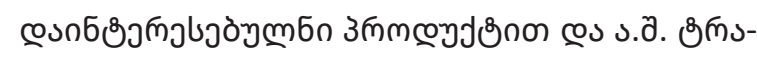

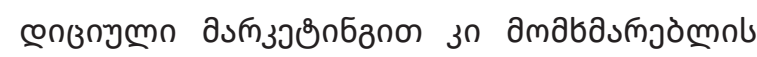

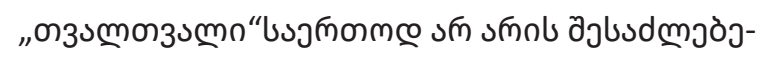

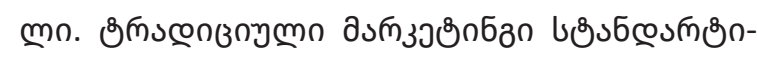

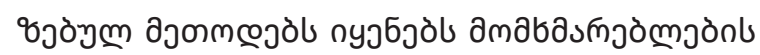

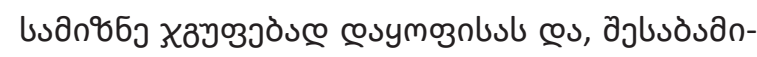

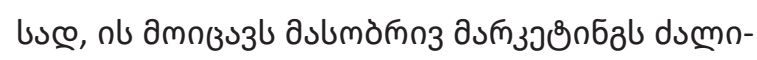

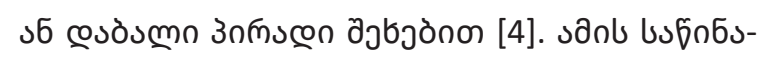

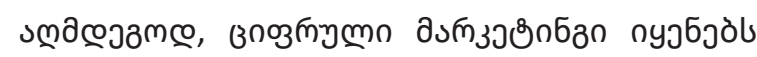

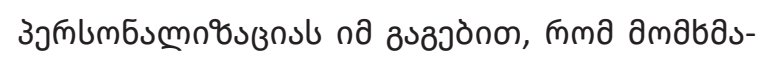

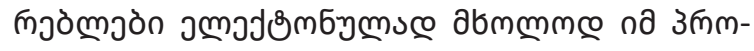

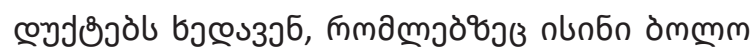

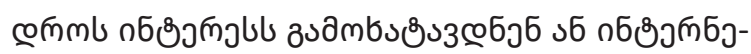

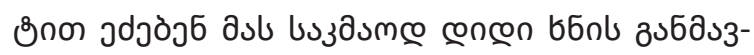

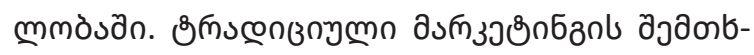

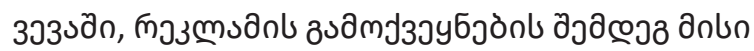

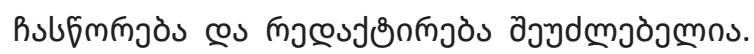

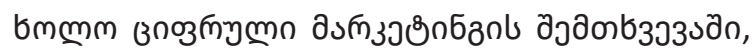

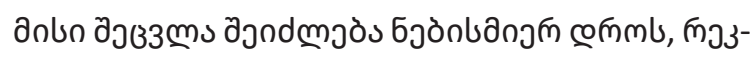

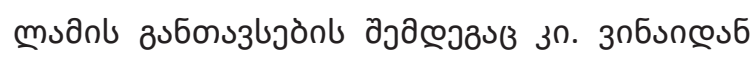

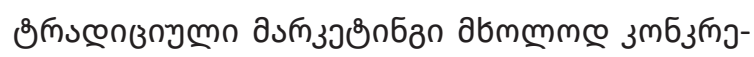

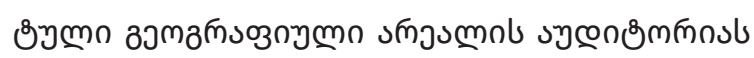

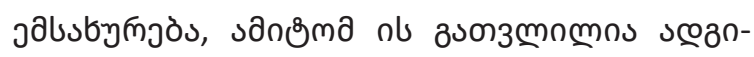

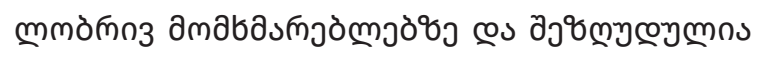

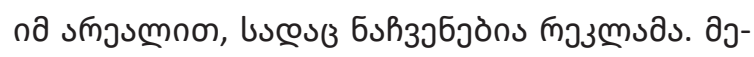

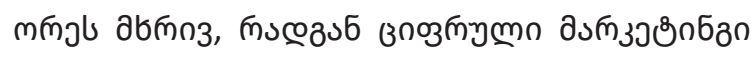

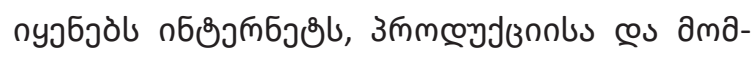

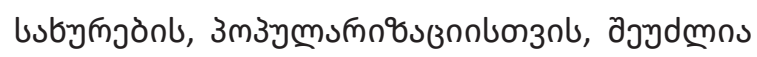

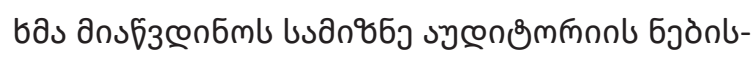

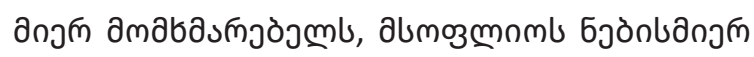

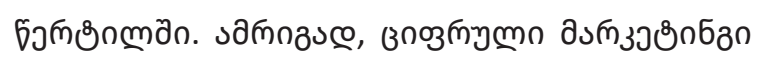

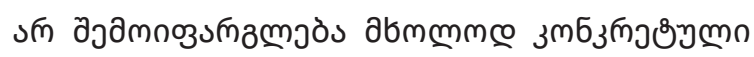

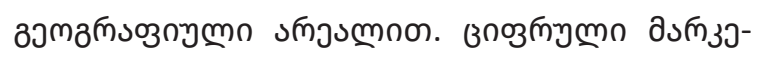

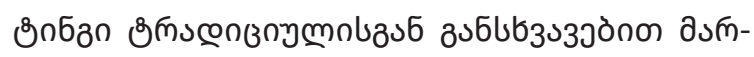

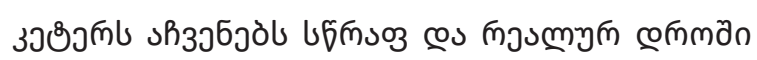

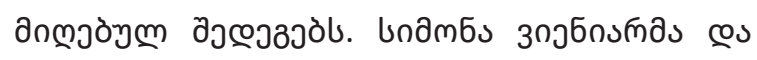

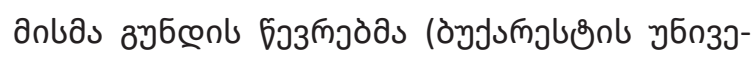

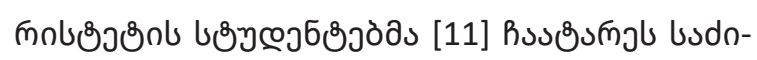

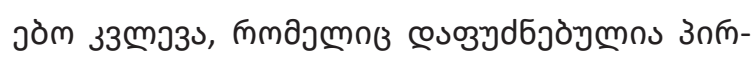

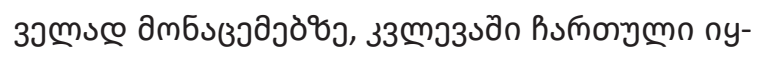

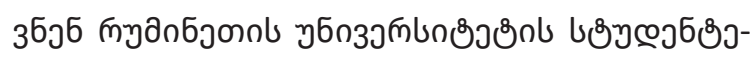

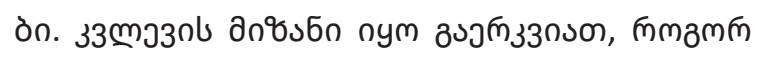

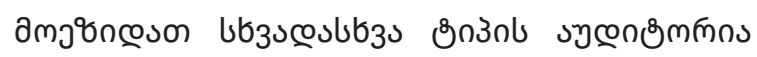

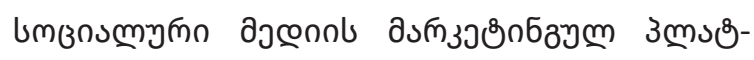

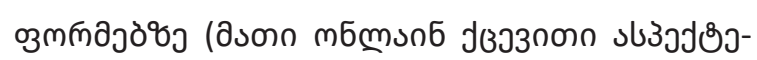

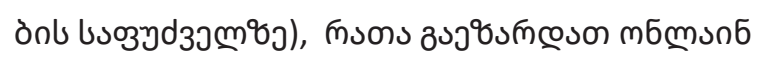

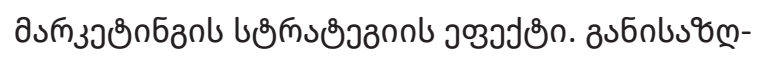

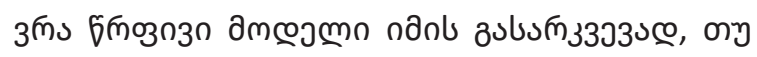

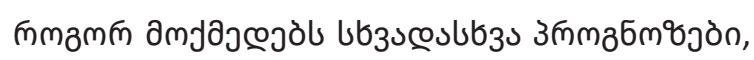

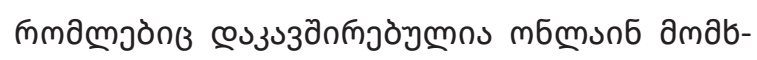

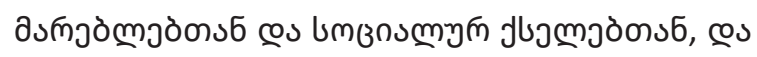




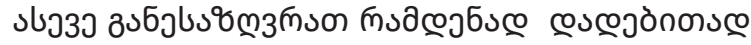

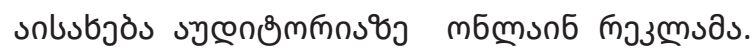

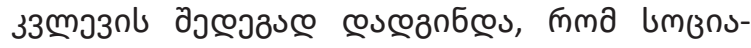

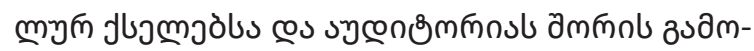

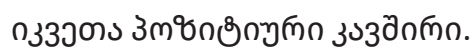

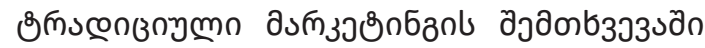

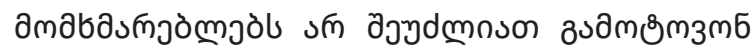

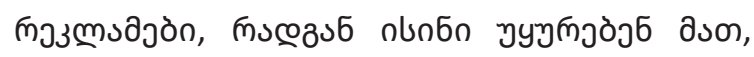

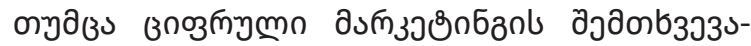

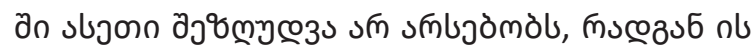

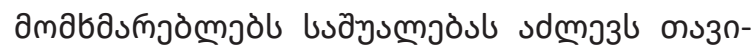

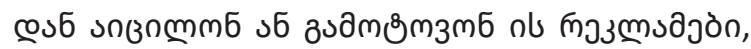

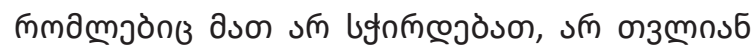

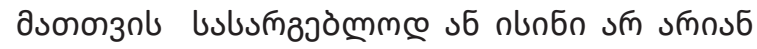

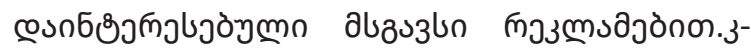

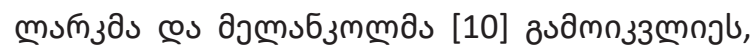

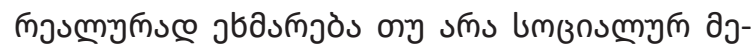

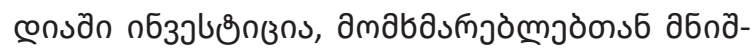

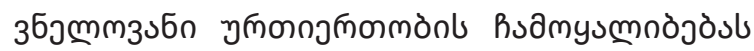

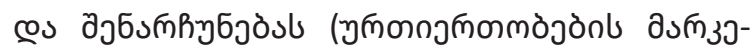

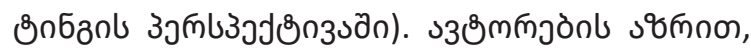

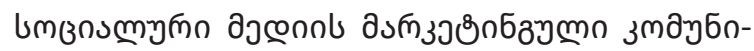

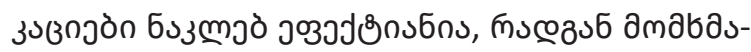

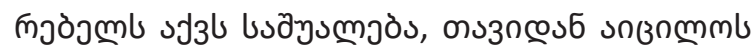

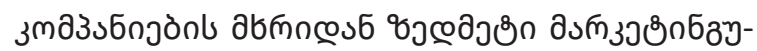

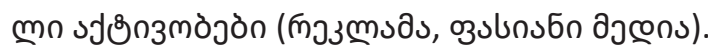

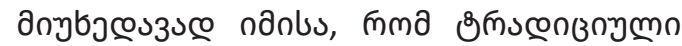

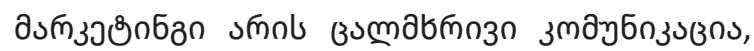

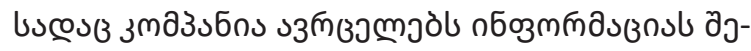

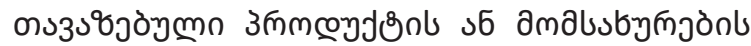

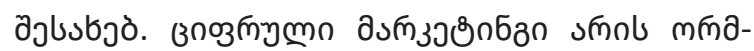

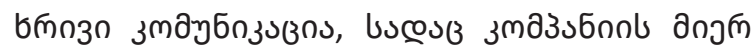

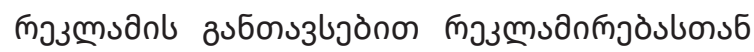

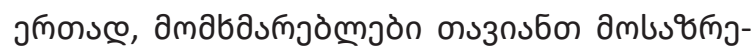

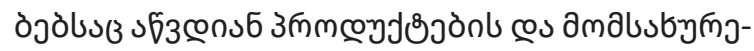

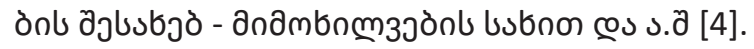

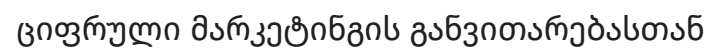

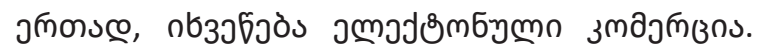

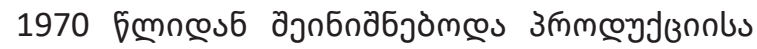

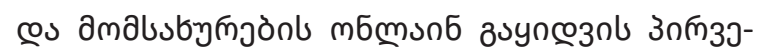

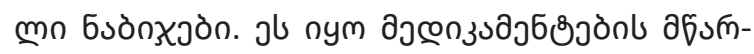

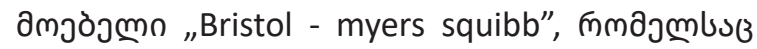

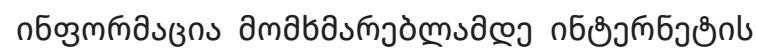

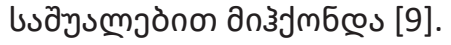

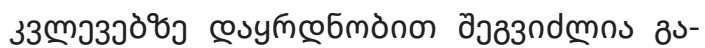

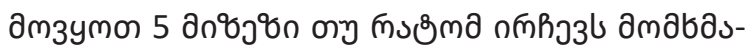

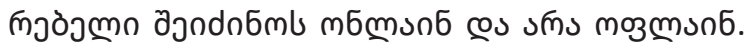

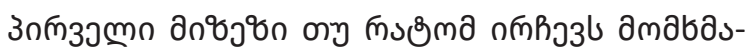

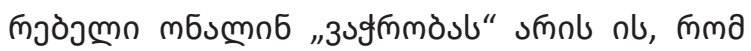

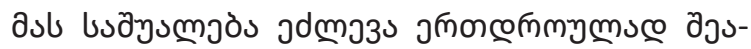

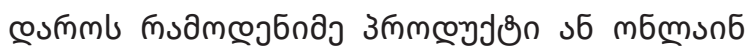

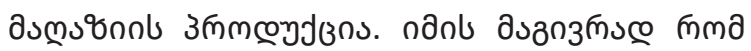

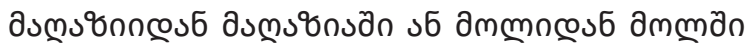

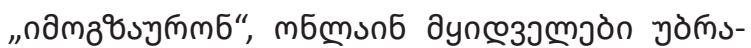

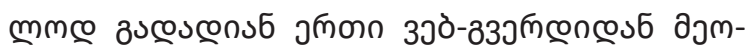

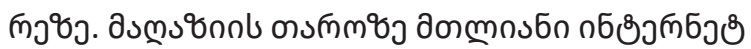

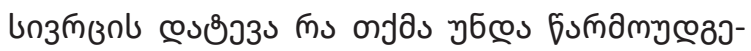

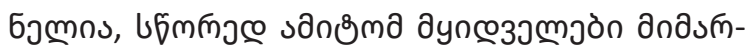

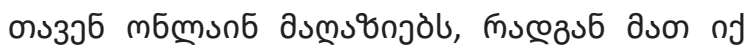

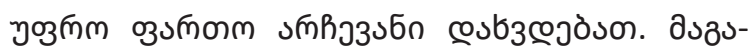

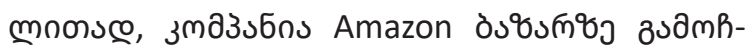

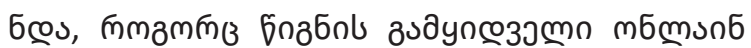

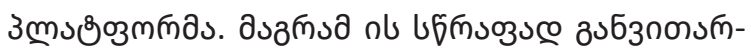

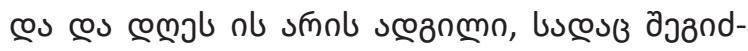

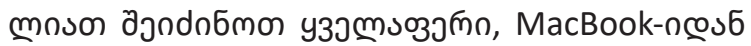

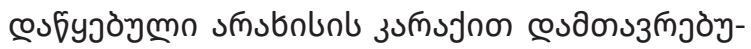

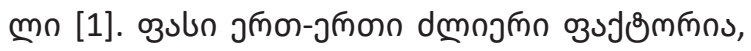

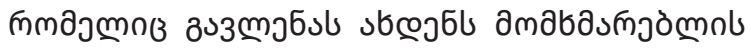

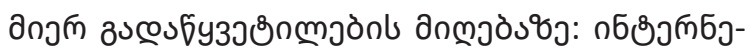

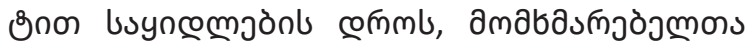

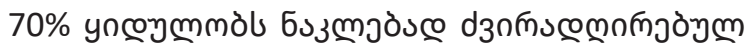

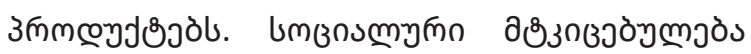

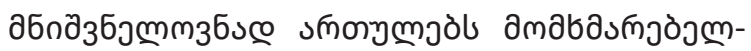

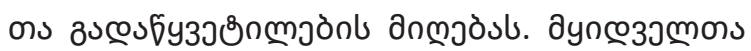

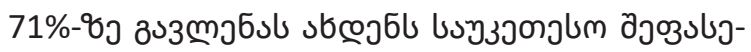

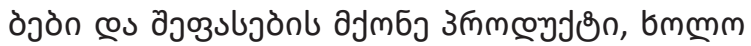

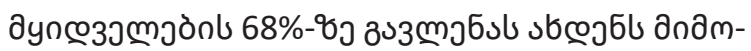

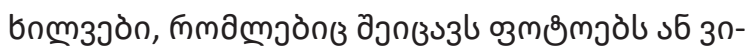

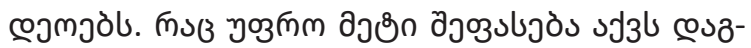

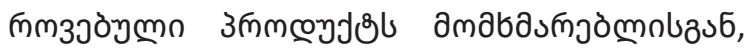

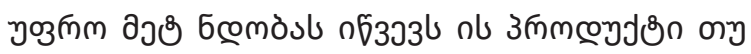

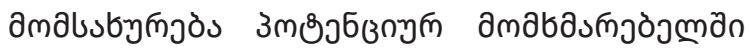

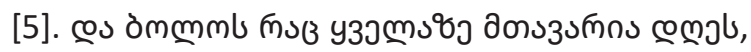

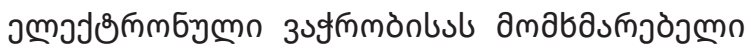

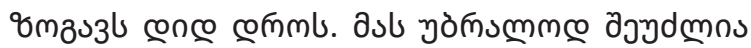

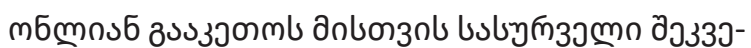




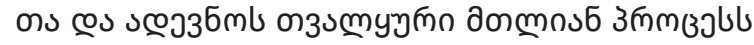

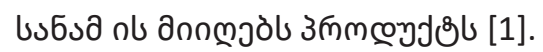

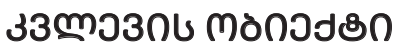

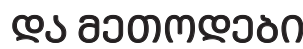

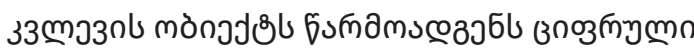

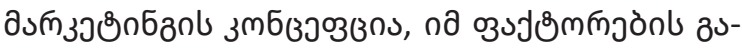

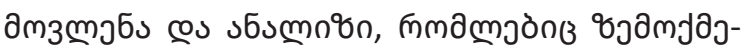

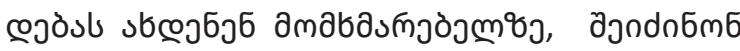

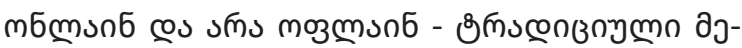

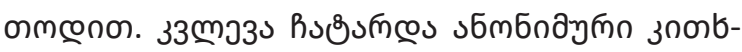

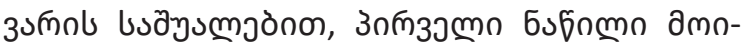

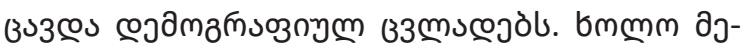

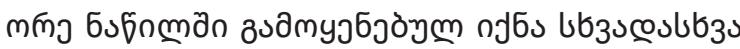

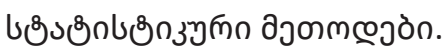

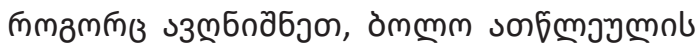

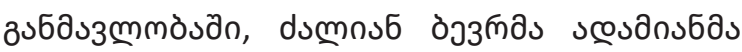

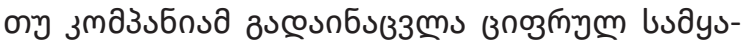

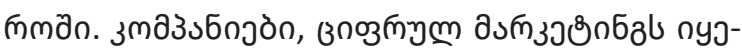

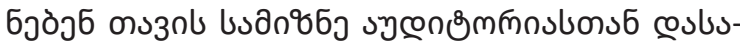

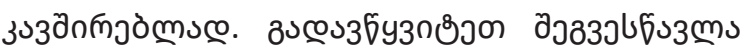

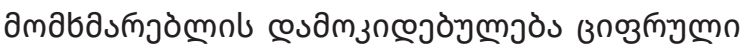

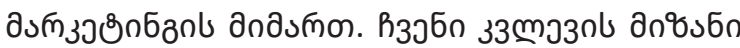

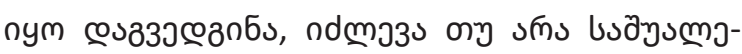

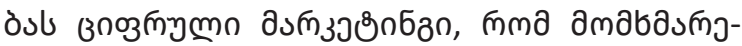

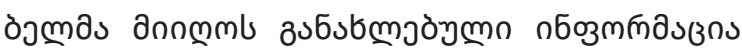

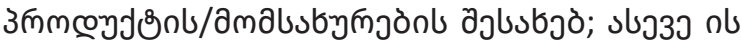

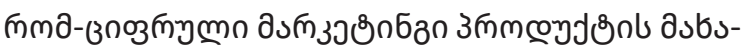

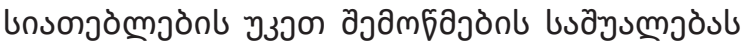

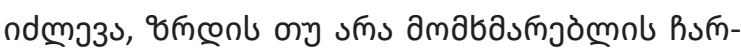

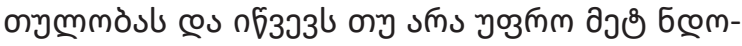

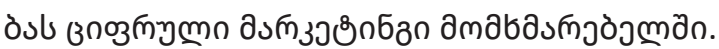

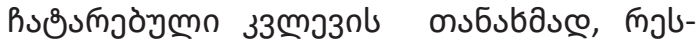

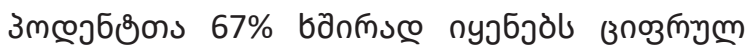

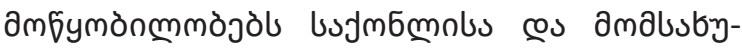

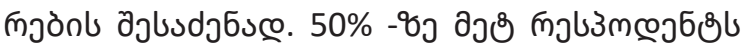

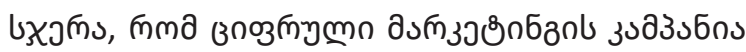

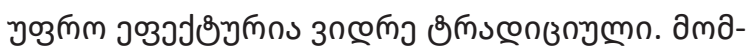

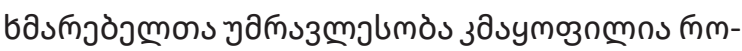

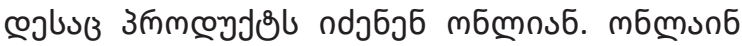

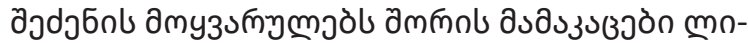

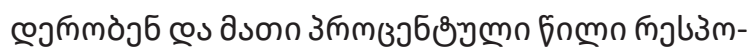

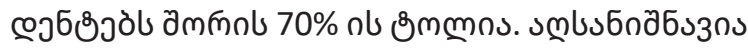

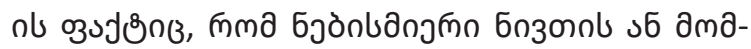

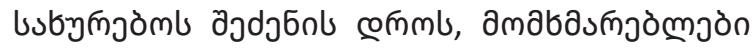

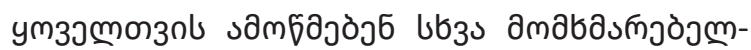

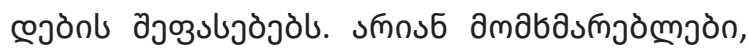

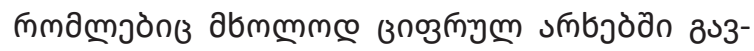

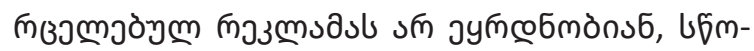

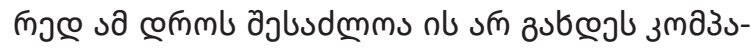

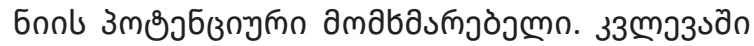

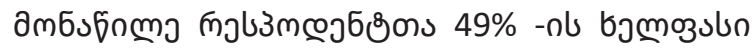

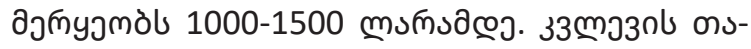

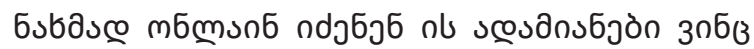

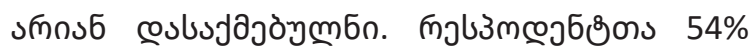

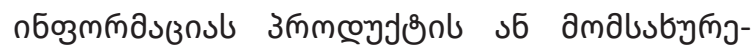

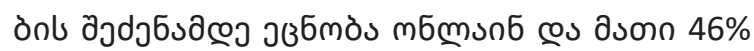

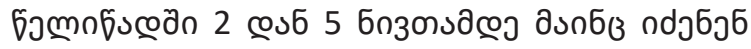

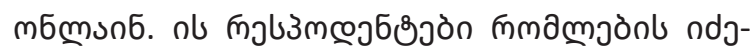

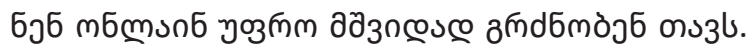

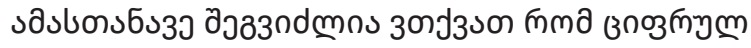

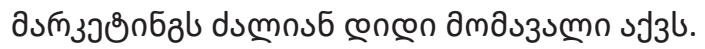

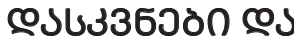 ตัзмวอธ๕รษกวัก}

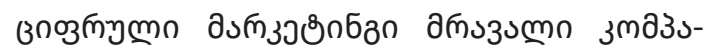

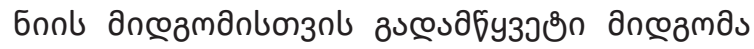

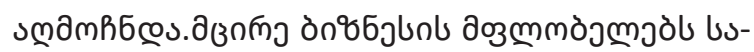

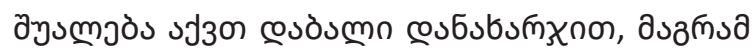

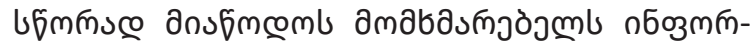

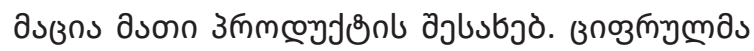

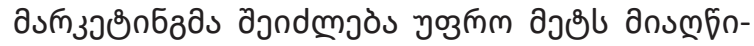

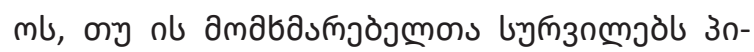

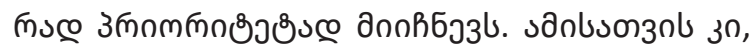

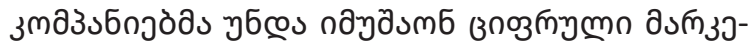

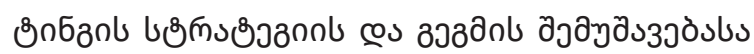

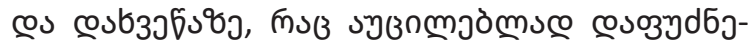

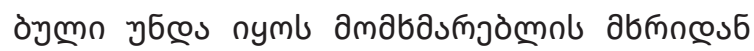

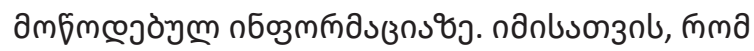

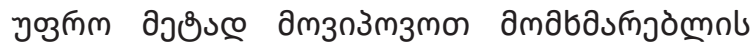

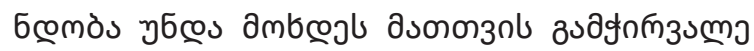




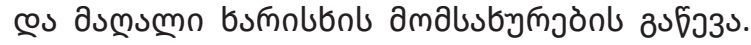

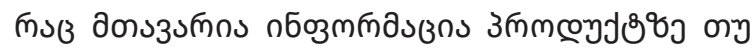

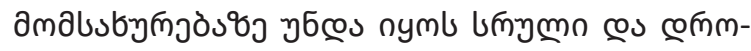

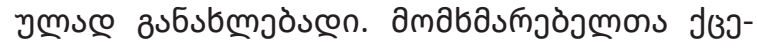

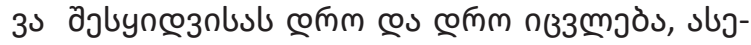

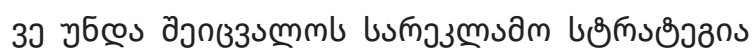

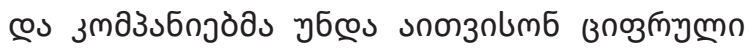

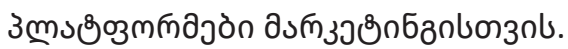

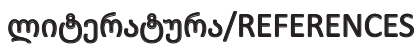

[1] 5 Reasons People Buy Products Online. (n.d.). Retrieved from https://www.crazyegg.com/blog/reasons-peoplebuy-products-online/

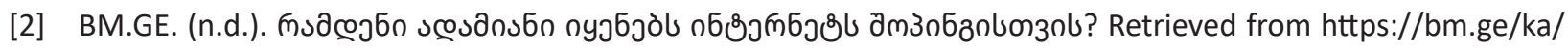
article/ramdeni-adamiani-iyenebs-internets-shopingistvis-/63653

[3] Difference Between Traditional Marketing and Digital Marketing - GeeksforGeeks. (n.d.). Retrieved from https:// www.geeksforgeeks.org/difference-between-traditional-marketing-and-digital-marketing/

[4] Difference Between Traditional Marketing and Digital Marketing (with Reasons, Forms, Examples and Comparison Chart) - Key Differences. (n.d.). Retrieved from https://keydifferences.com/difference-betweentraditional-marketing-and-digital-marketing.html

[5] Top Reasons Consumers Shop Online - Why Online Shopping is Popular. (n.d.). Retrieved from https://www. junglescout.com/blog/reasons-consumers-shop-online/

[6] Traditional Marketing vs Digital Marketing | 10 Amazing Key Differences. (n.d.). Retrieved from https://www. educba.com/traditional-marketing-vs-digital-marketing/

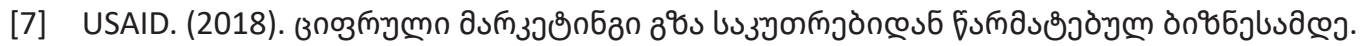

[8] We Are Social. (n.d.). Digital 2020: 3.8 billion people use social media. Retrieved from https://wearesocial.com/ blog/2020/01/digital-2020-3-8-billion-people-use-social-media

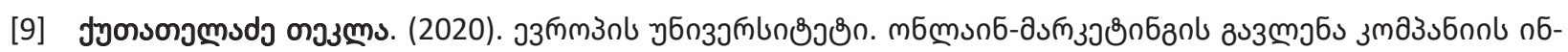

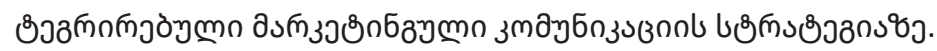

[10] Clark, M., \& Melancon, J. (2013). The Influence of Social Media Investment on Relational Outcomes: A Relationship Marketing Perspective. International Journal of Marketing Studies, 5(4). doi: 10.5539/ijms.v5n4p132

[11] Vinerean, S., Cetina, I., Dumitrescu, L., \& Tichindelean, M. (2013). The Effects of Social Media Marketing on Online Consumer Behavior. International Journal of Business and Management, 8(14). doi: 10.5539/ijbm. v8n14p66

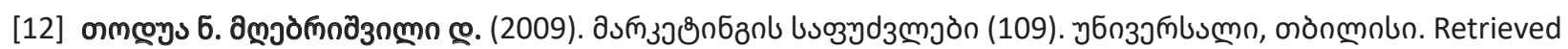
from

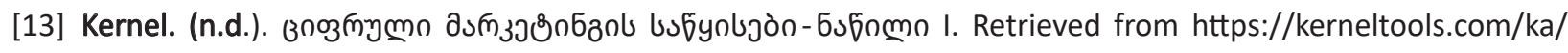
post/cifruli-marketingis-sawkisebi/

[14] simplilearn. (n.d.). The History and Evolution of Digital Marketing. Retrieved from https://www.simplilearn. com/history-and-evolution-of-digital-marketing-article 